\author{
P. Freitag - M.W. Greenlee $\cdot$ T. Lacina $\cdot$ K. Scheffler \\ E.W. Radï
}

\title{
Effect of eye movements on the magnitude of functional magnetic resonance imaging responses in extrastriate cortex during visual motion perception
}

Received: 16 July 1997 / Accepted: 14 October 1997

\begin{abstract}
We have studied the effects of pursuit eye movements on the functional magnetic resonance imaging (fMRI) responses in extrastriate visual areas during visual motion perception. Echoplanar imaging of 10-12 image planes through visual cortex was acquired in nine subjects while they viewed sequences of random-dot motion. Images obtained during stimulation periods were compared with baseline images, where subjects viewed a blank field. In a subsidiary experiment, responses to moving dots, viewed under conditions of fixation or pursuit, were compared with those evoked by static dots. Eye movements were recorded with MR-compatible electro-oculographic (EOG) electrodes. Our findings show an enhanced level of activation (as indexed by blood-oxygen level-dependent contrast) during pursuit compared with fixation in two extrastriate areas. The results support earlier findings on a motion-specific area in lateral occipitotemporal cortex (human V5). They also point to a further site of activation in a region approximately $12 \mathrm{~mm}$ dorsal of V5. The fMRI response in V5 during pursuit is significantly enhanced. This increased response may represent additional processing demands required for the control of eye movements.
\end{abstract}

Key words Functional MRI - BOLD effect · Motion perception · Oculomotor pursuit · Human

\section{Introduction}

The ability to detect object motion is an important feature of biological visual systems. Electrophysiological recordings in the macaque brain have isolated more than 30 vi-

P. Freitag · T. Lacina · E.W. Radü

Department of Neuroradiology, University Hospital Basel,

CH-4031 Basel, Switzerland

M.W. Greenlee ( $)$

Department of Neurology, University Hospital Freiburg, Breisacherstrasse 64, D-79106 Freiburg, Germany

K. Scheffler

MR-Center, University of Basel, CH-4031 Basel, Switzerland sually responsive areas (Van Essen and Zeki 1978; Van Essen et al. 1981; Felleman and Van Essen 1991). Different areas in the extrastriate cortex have been identified that respond selectively to the direction and speed of moving stimuli (Albright et al. 1984; Mikami et al. 1986; Newsome et al. 1986; Tanaka et al. 1989). Area MT (also known as V5) is in the fundus of the superior temporal sulcus in macaque monkeys, and cells in this area respond well to most forms of stimulus motion. Adjacent to MT there is another motion-specific area, referred to as MST (middle superior temporal, or V5a), which selectively responds to ecologically relevant forms of stimulus motion such as expansion and contraction or rotation (Tanaka et al. 1986; Tanaka and Saito 1989). Area MST is also involved in the control of smooth-pursuit eye movements (Lisberger et al. 1987; Dürsteler and Wurtz 1988; Komatsu and Wurtz 1988). These results suggest that complex motion information, together with extraretinal signals about eye speed and gaze position, could be used to calculate optic flow and heading (Bradley et al. 1996; Andersen 1997; Duffy and Wurtz 1997). Area $\mathrm{V} 3$, which receives inputs from V1 and V2 and projects to V5, has also been shown to contain a subset of motion-selective cells (Gegenfurtner et al. 1997). In addition, the anterior superior temporal polysensory area (STPa) in macaque appears to contain neurons with complex, motion-selective response characteristics (Oram and Perrett 1996).

With the advent of functional magnetic resonance imaging (fMRI), it has become possible to noninvasively map hemodynamic responses to sensory and cognitive stimulation in human brain. T2*-weighted MR imaging can reveal changes in the blood supply and blood oxygenation in activated brain areas (Ogawa et al. 1990, 1992; Kwong et al. 1992; Turner et al. 1993). Fast imaging sequences such as echoplanar imaging (EPI) can capture stimulus-evoked transient changes in blood oxygenation level-dependent (BOLD) contrast (Bandettini et al. 1992; Ernst and Hennig 1994; Menon et al. 1995).

In a recent fMRI study, Tootell et al. (1995) described an area located in the lateral occipital-temporal cortex, 
ranging over subjects between $8 \mathrm{~mm}$ above the anterior and posterior commissural (AC-PC) plane and $12 \mathrm{~mm}$ below it. An additional area located more dorsally, approximately $16-24 \mathrm{~mm}$ above the AC-PC plane, has also been reported (Lacina et al. 1995). This area lies posterior to and dorsal of V5 and has tenatively been referred to as human V3a (Tootell et al. 1997; Smith et al. 1997), which may correspond to the kinetic occipital area identified by Orban and colleagues (Dupont et al. 1997; Van Oostende et al. 1997). Selective changes in regional cerebral blood flow (rCBF) in response to visual motion stimulation had already been demonstrated in earlier positron emission tomography (PET) studies (Corbetta et al 1991; Zeki et al. 1991; Watson et al. 1993; Cheng et al. 1995). Focal lesions in lateral occipitotemporal and occipitoparietal cortex have been shown to impair visual motion processing (Plant et al. 1993; Barton et al. 1995; Greenlee et al. 1995; Greenlee and Smith 1997) and reduce the gain of pursuit (Kimmich et al. 1995; Barton et al. 1996a). It is well known that unidirectional object motion evokes pursuit eye movements (Lisberger et al. 1987). Although the subjects in earlier studies were instructed to fixate a centrally located point, some residual pursuit eye movements could have occurred. In this study we determine the effects of pursuit eye movements on fMRI responses in extrastriate areas during visual motion perception.

\section{Materials and methods}

Imaging was performed with a 1.5-T clinical scanner (Siemens Magnetom Vision; Siemens, Erlangen) using a standard radio frequency (RF) receive-transmit headcoil. Sagittal T1-weighted images were obtained to define the anterior-posterior commissural (AC-PC) plane (Talairach and Tournoux 1988) for later mapping. Axial images were also acquired parallel to the AC-PC plane. A volume consisted of 10-12 contiguous 4-mm slices located -14 to $+34 \mathrm{~mm}$ above and below the AC-PC plane. Shimming was performed for the entire brain using an autoshim routine, which yielded satisfactory magnetic field homogeneity.

Functional imaging was performed with $\mathrm{T} 2 *$-weighted, gradientrecalled EPI. The technical data for the functional measurements were TE $70 \mathrm{~ms}$, TR $5 \mathrm{~s}$, flip angle $90^{\circ}$, field of view $250 \mathrm{~mm}$, matrix $128 \times 128$, resulting in a voxel size of $1.95 \times 1.95 \times 4.0 \mathrm{~mm}$. The stimulation protocol of each functional series consisted of six 50-s intervals with three alternating periods of rest (off) and stimulation (on). This protocol yielded 60 echoplanar volumes acquired over a 5-min period.

To minimize head motion, the subject's head was fixed with a vacuum cap. Despite these precautions, residual head motion was still evident in some of the image data. In-plane motion could be corrected by applying an image alignment algorithm (Cox 1996). Excessive out-of-plane motion could not be corrected by this algorithm. However, we could detect such head motion, and the images affected were removed from further analysis.

The subjects viewed the stimuli through a pair of Plexiglas prisms. The stimuli were created on a Macintosh computer. Using an LCD projector (Sony), they were backprojected onto a transluminant screen within the gantry. The image subtended $60 \times 30^{\circ}$ of visual angle $(180 \times 90$ pixels $)$.

The motion stimuli were limited-lifetime random-dot sequences. Black dots moved on a gray background (luminance contrast $50 \%$ ). There were two different coherent dot motion directions, either expansion-contraction or frontoparallel. A total of $90 \%$ of the dots were moving in the coherent direction, $10 \%$ of the dots moved in random directions (Fig. 1a). The motion direction changed every $3 \mathrm{~s}$ (from expansion to contraction or from upwards to downwards). The dots were 3 pixels in diameter, the dot speed was $5 \%$ s. In addition, a stationary white fixation spot was presented in the center of the display.

The subjects performed two tasks: In the first task they fixated a central spot and viewed motion stimuli. In the second task, they were asked to pursue, with their eyes, the dots moving in the coherent direction. During both conditions, subjects were instructed to attend to the coherently moving dots. During the off period the central fixation point was presented on a background of the same mean luminance $\left(60 \mathrm{~cd} / \mathrm{m}^{2}\right)$ and subjects were requested to fixate it. Four runs were completed per subject in random order within a single recording session. The four conditions were as follows: (1) expansioncontraction dot motion with fixation and (2) pursuit; (3) frontoparallel dot motion with fixation and (4) pursuit.

Fixation and pursuit were monitored by electro-oculography (EOG). We used MR-compatible electrodes consisting of a graphite disk submerged in electrolytic gel (Conmed). Pilot measurements on water phantoms indicated that these electrodes had no noticeable effect on field homogeneity. Analysis of the resulting EOG showed small deflections of the EOG baseline in the fixation condition. This effect is caused by the stationary magnetic field of the MR scanner (Felblinger et al. 1996). Additional artifacts in the EOG during scanning depend on the MR sequence applied. The EPI sequence used in this study had only minimal effects on the EOG.

During the scans, we typically observed some eye blinks, but the frequency was similar for both baseline and stimulation periods. The EOG in the pursuit task clearly indicated that most of the subjects followed the instructions. We could also monitor any undesired eye movements during the fixation task and the baseline periods, which only occurred infrequently.

The functional data were first corrected for head motion and then analyzed with pixel-wise Student's $t$-tests to isolate significantly activated voxels. The significance level applied was $t=2.0, P=0.05$ (uncorrected for multiple comparisons). The time courses of the significant voxel clusters were inspected and compared with the on-off stimulus boxcar. Size and significance level of the activation in the regions of interest (ROIs) were used to compare the fMRI activation between the four different conditions. Activation within ROIs was quantified by weighting the number of significantly activated voxels by their $t$-values. ANOVA was used to determine the level of significance of the experimental task (fixation or pursuit) and motion type (expansion-contraction or frontoparallel).

After giving their informed consent, 15 volunteers participated in the study. Two subjects had to be excluded, because they did not follow the instructions properly. Data from four more subjects had to be excluded because of excessive head motion that could not be corrected by in-plane image alignment. This relatively high exclusion rate can be explained by the difficulty of making pursuit eye movements without concomitant head motion. Data from seven men and two women thus form the database. The subject's age ranged from 26 to 35 years, mean age 29.4 years. One volunteer was left-handed, the remaining eight were right-handed.

\section{Results}

A typical MR-signal time course is shown in Fig. 1b. Significant MR signal change in the ROI occurs during visual motion stimulation and this MR signal is enhanced by eye movements. The delay of the fMRI response after stimulus onset can also be seen in the time course (Ogawa et al. 1992; Ernst and Hennig 1994).

All subjects exhibited significant activation in V1 and V2 in both hemispheres. Additional bilateral activation in the lateral extent of Brodmann's area 19 and 37 (BA 19/ 37) was evident. Figure 2 presents the results of one sub- 

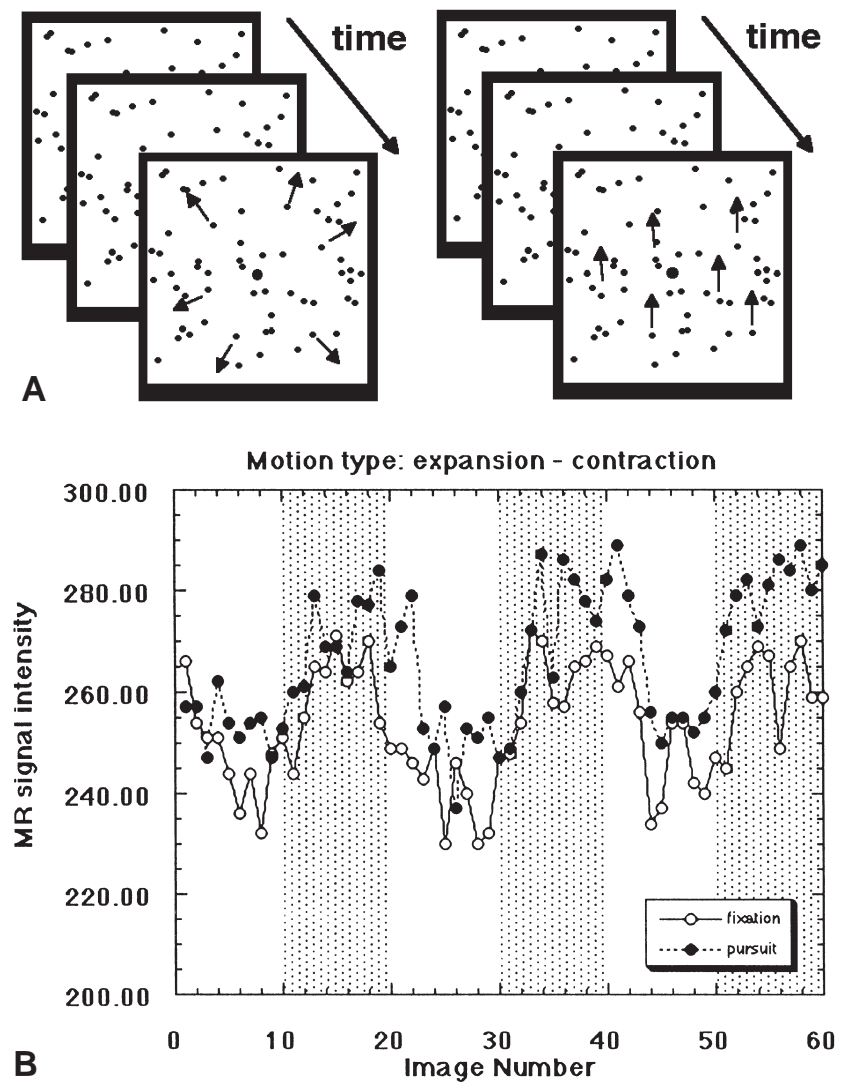

ject for the condition with fixation (left panel) and pursuit (right panel). There is a visible increase in the signal intensity during pursuit in the lateral occipitotemporal areas. This extrastriate area, ranging from $+8 \mathrm{~mm}$ above AC-PC to $-12 \mathrm{~mm}$ below (ventral BA 37), was activated in each subject in both motion conditions with fixation, in eight subjects in both hemispheres, in one right-handed subject only in the left hemisphere. There was a significant increase in activation with pursuit in each subject in both hemispheres. In all subjects, the activated clusters showed an increase in size and intensity (Fig. 3). The size of this increase varied somewhat among subjects (error bars in Fig. 3).

Less frequently a more dorsal extrastriate area, ranging from +20 to $+28 \mathrm{~mm}$ above AC-PC, exhibited clusters of significantly activated voxels. Two subjects showed significant activation during fixation in the left hemisphere, a further subject showed activation in both hemispheres. This activation in all three subjects was enhanced by eye movements. Three further subjects showed significant activation only during pursuit, two of these only in the left hemisphere, one in both hemispheres. The final three subjects showed no activation in this dorsal extrastriate area.

An ANOVA was performed to test the effects of motion type and task on the relative ROI intensity. This revealed a significant effect of eye movements on the MR signal intensity $\left(F_{1,25}=20.5 ; P=0.0001\right)$, but no significant difference in the effect of the type of motion (expansioncontraction or frontoparallel; $F_{1,25}=2.6$; n.s.). Also the in-
Fig. 1 a Schematic illustration of the stimuli and their motion directions (arrows) used in the experiments. b Typical time course of MR signal intensity as a function of time. Stippled columns signify stimulation periods. The left panel presents the results for expansioncontraction motion and the right panel shows the results for frontoparallel motion
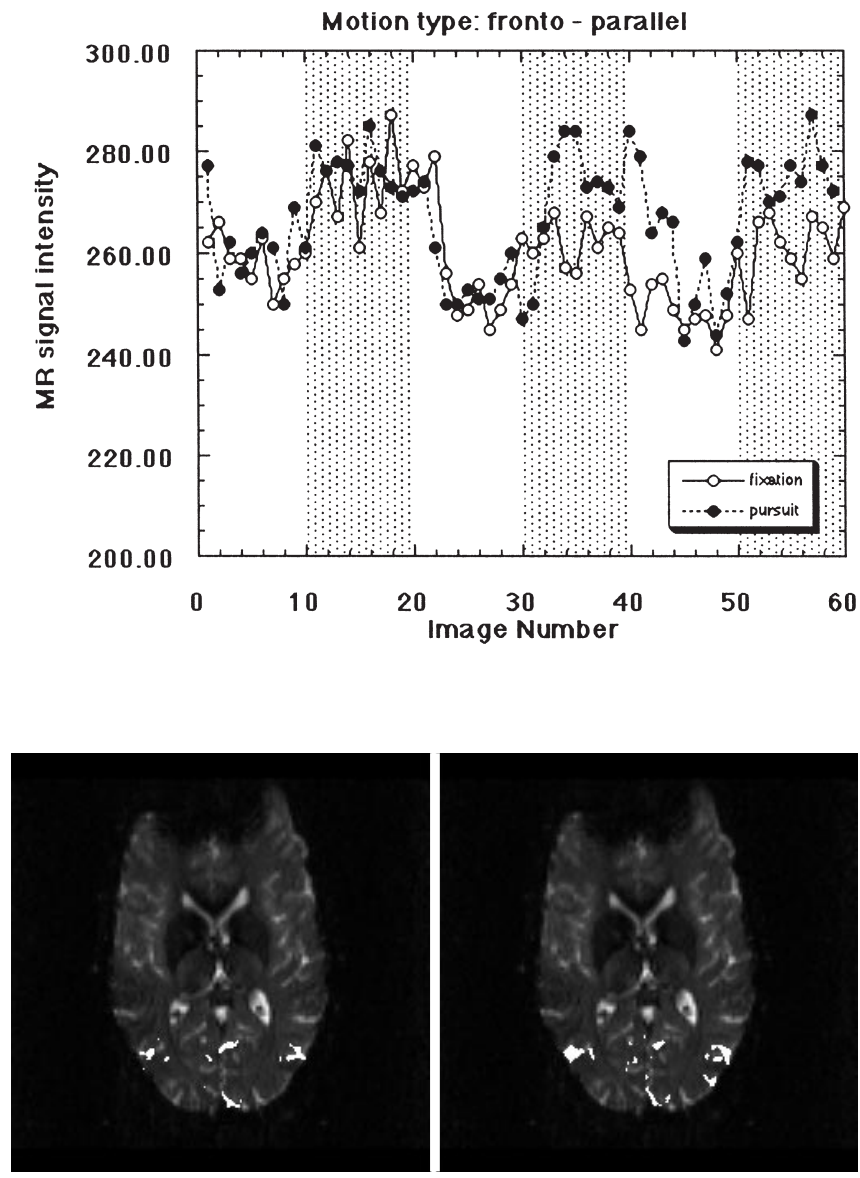

Fig. 2 The overlay of the functional magnetic resonance imaging (fMRI) response on an echoplanar image from one subject (female, 31 years old) $8 \mathrm{~mm}$ above the AC-PC plane. Significant blood oxygenation level-dependent contrast effects are evident during motion viewing either with central fixation (left panel) or with pursuit (right panel). For better visualization, only significantly activated pixels with a $t \geq 5$ are shown (uniformly white)

teraction between task and motion type was not significant $\left(F_{1,25}=0.62 ;\right.$ n.s. $)$, nor was the effect of hemisphere significant $\left(F_{1,25}=1.2 ;\right.$ n.s. $)$.

The results shown in Figs. 2 and 3 could be difficult to interpret, since both fixation and pursuit conditions are compared with a baseline condition without any visual stimulation. Thus the BOLD responses contain both motion-specific and nonspecific components. To better examine the role of pursuit during motion perception, we 
A

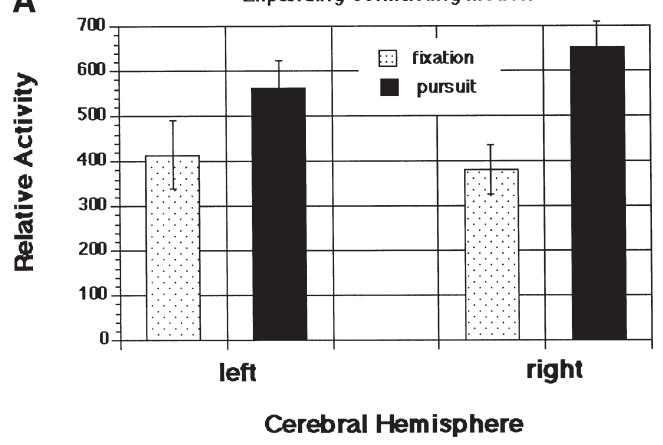

B

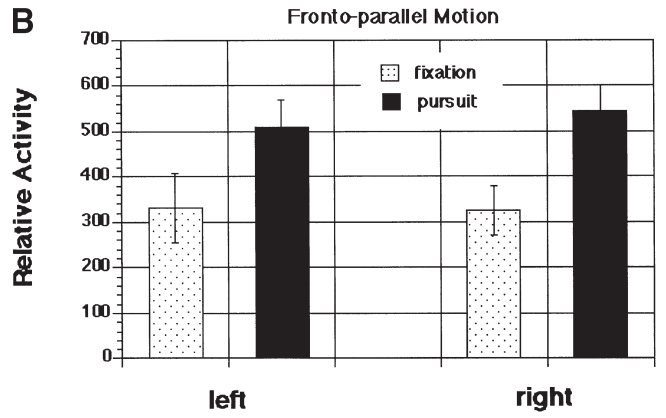

Cerebral Hemisphere

Fig. 3a, b Relative activity within the occipitotemporal region of interest (ROI; number $\times$ mean $t$-value of significant activated pixels) is shown for left and right hemispheres for the two types of motion under study: a expanding-contracting, b frontoparallel direction. Stippled columns show the results during fixation, black columns show those during pursuit. The results show the mean values for nine subjects. Error bars represent $\pm 1 \mathrm{SD}$

performed a further control experiment on two subjects. The results of this control condition are shown in Fig. 4. Two aspects of this experiment are different from those described above. First, during the baseline condition, subjects were presented with a field of stationary dots. The dots were identical to those described in the Materials and methods section except that they were stationary. Stimulation periods consisted either of motion displays during which the subjects held central fixation or performed pursuit eye movements. For the condition requiring fixation, a centrally located white dot was presented and the subject was instructed to fixate it while attending to the coherent motion in the display. For the pursuit condition, no fixation point was given and the subject was instructed to pursue the coherently moving dots $(90 \%$ of all dots). Frontoparallel motion (left-right) was used and the stimulus direction changed every $2 \mathrm{~s}$. Figure 4 presents the results from two measurements for one subject. The time course of signal activiation is shown in Fig. 4a, and the activated areas in occipital, occipitotemporal, and occipitoparietal cortex are shown in Fig. 4b. Compared with the baseline condition with static dots, dot motion evoked greater overall responses in visual cortex. In both subjects, pursuit evoked a stronger BOLD response in the V5/V5a area compared with the condition requiring fixation.
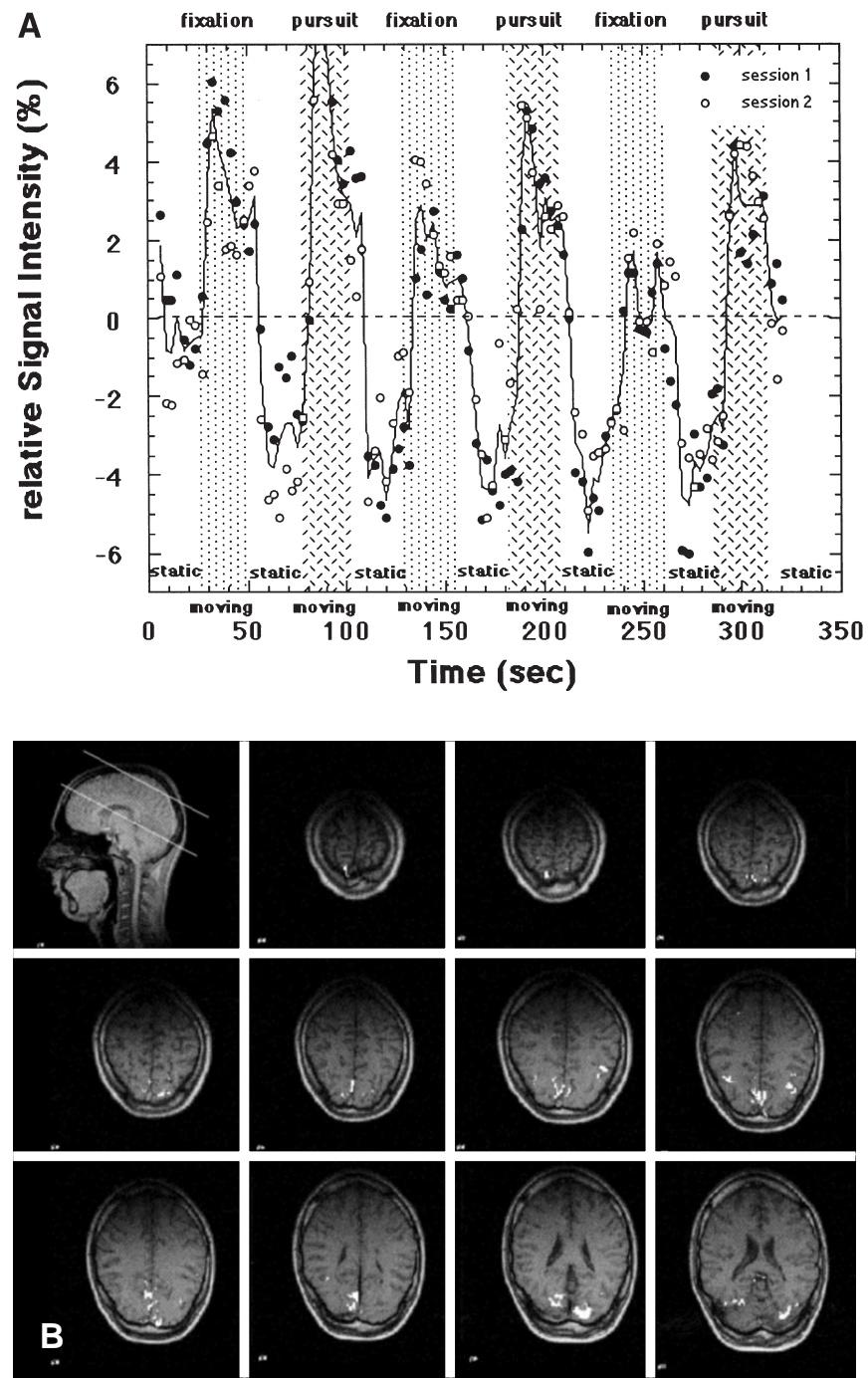

Fig. 4 a Relative signal intensity within the occipitotemporal ROI (averaged over hemispheres) is shown as a function of the time course. White bars indicate time periods during which the display contained stationary dots, light stippled bars show the time periods in which the dots were moving and the subjects were required to fixate a central dot, and the dark stippled bars depict the time periods where the subjects were required to pursue the dots moving in the coherent direction. Solid symbols and open symbols present the results of one subject in each of two measurements. The solid line depicts the mean blood oxygenation level-dependent contrast signal. b Axial T1-weighted anatomical images with functional overlays depicting significant activation during motion perception for one subject. Eleven axial slices are shown

\section{Discussion}

Pursuit eye movements during motion perception evoked a significantly larger BOLD contrast effect in the ROIs investigated in this study. In all subjects the activation was increased in size and intensity. Our ROI analysis (Fig. 3) indicated a highly significant effect of the task (i.e., fixation compared with pursuit), but no effect of the motion type (expansion-contraction compared with frontoparallel). The area showing the largest motion 
evoked response was in the lateral occipitotemporal region in BA 37 bordering BA 19 (Fig. 2). These results are consistent with those of earlier investigations (Cheng et al. 1995; Lacina et al. 1995; Tootell et al. 1995; DuPont et al. 1997), showing a lateral occipitotemporal activation during motion perception. Although not the subject of this study, it has been recently shown that the frontal eye fields (FEF) in monkeys may also be involved in the control of pursuit eye movements (Gottlieb et al. 1993), and lesions in FEF appear to disrupt pursuit (Lynch 1987). Technical limitations at the time of study did not allow us to coregister striate/extrastriate cortex, V5/V5a, and the FEF in prefrontal cortex (BA 6). In the subsequently performed control experiment (Fig. 4), in which FEF could also be imaged along with visual cortex, we were unable to detect significant activity in these frontal areas during pursuit. However, a recent fMRI study (Petit et al. 1997) indicates that discrete activation can be evoked in the FEF during pursuit. The reported location is more inferior and lateral to the activation evoked by visually guided saccades.

One plausible explanation for the enhanced effect during pursuit is that the eye movements, although reducing retinal motion with respect to the pursued dots, could have increased retinal motion for the remaining dots. This effect would be most pronounced for the expansion-contraction condition with radial motion vectors. Since the pursuit enhancement is also evident for the frontoparallel direction, where $90 \%$ of the dots moved in the same direction, this argument does not appear convincing. The pursuit-evoked increase in BOLD contrast could also reflect a more general increase in attention or vigilance required in the pursuit task (Barton et al. 1996b; Nobre et al. 1997). Indeed, two recent studies (O'Craven et al. 1997; Beauchamp et al. 1997) have shown that attention to the motion component of complex stimulus displays indicate that the activity of human V5, as indexed by BOLD contrast, can be enhanced by selective attention to the motion in the display. The effect of attention alone, however, is not sufficient to account for the present results. Subjects were instructed to attend to the coherent motion (90\% of all dots) in both fixation and pursuit tasks, so that the large effects found here can hardly be accounted for by slight differences in attentional demands between the two tasks. We do not, however, rule out that attentional effects could be partially involved in the enhancement found during pursuit. Further experiments, designed specifically to address this aspect of the results, are needed to dissociate the effects related to attentional demands and pursuit.

We contend that the signal enhancement associated with the pursuit task is related to the additional processing requirements of the human motion areas located in occipitotemporal cortex. Direction and speed signals must be combined to enable the oculomotor system to engage in active pursuit of a target among moving distractors. In addition, extraretinal signals that provide information about eye position and/or eye speed must enter into the calculations required to determine the relative components of object and self motion. We propose that these additional processing demands lead to an enhanced neural activation and thus to concomitant changes in regional blood oxygenation in the motion areas studied. The human V5/V5a complex might be the first site in the visual system where information about object and self-motion (e.g., eye movements) can be conjointly used to determine the location, direction, and speed of objects in visual space. In the light of the present results, it would seem reasonable to monitor eye movements during fMRI, since the results of many experiments could potentially be confounded by the presence or absence of eye movements.

Acknowledgements This work was funded by the Swiss National Foundation for Science (to E.W. Radï). M.W. Greenlee is supported by the Hermann and Lilly Schilling Foundation, Germany. The authors would like to thank the volunteers for their participation.

\section{References}

Albright TD, Desimone R, Gross CG (1984) Columnar organization of directionally selective cells in visual area MT of the macaque. J Neurophysiol 51:16-31

Andersen RA (1997) Neural mechanisms of motion perception in primates. Neuron 18:865-872

Bandettini PA, Wong EC, Hinks RS, Tikofsky RS, Hyde JS (1992) Time course EPI of human brain function during task activation. Magn Reson Med 25:390-397

Barton JJS, Sharpe JA, Raymond JE (1995) Retinotopic and directional defects in motion discrimination in humans with cerebral lesions. Ann Neurol 37:665-675

Barton JJS, Sharpe JA, Raymond JE (1996a) Directional defects in pursuit and motion perception in humans with unilateral cerebral lesions. Brain 119:1535-1550

Barton JJS, Simpson T, Kiriakopoulos E, Stewart C, Crawley A, Guthrie B, Woods M, Mikulis D (1996b) Functional MRI of lateral occipitotemporal cortex during pursuit and motion perception. Ann Neurol 40:387-98

Beauchamp MS, Cox RW, DeYoe EA (1997) Graded effects of spatial and featural attention on human area MT and associated motion processing areas. J Neurophysiol 78:516-520

Bradley DC, Maxwell M, Andersen RA, Banks MS, Shenoy KV (1996) Neural mechanisms of heading perception in primate visual cortex Science 273:1544-1547

Cheng K, Fujita H, Kanno I, Miura S, Tanaka K (1995) Human cortical regions activated by wide-field visual motion: $\mathrm{An} \mathrm{H}_{2}{ }^{15} \mathrm{O}$ PET study. J Neurophysiol 74:413-427

Corbetta M, Miezin FM, Dobmeyer S, Shulman GL, Petersen SE (1991) Selective and divided attention during visual discriminations of shape, color and speed: functional anatomy by positron emission tomography. J Neurosci 11:2383-2402

Cox R (1996) AFNI: software for analysis and visualization of functional magnetic neuroimages Comput Biomed Res 29 162-173

Duffy CJ, Wurtz RH (1997) Medial superior temporal area neurons respond to speed patterns in optic flow. J Neurosci 17:28392851

Dupont P, De Bruyn B, Vandenberghe R, Rosier AM, Michiels J, Marchal G, Mortelsmans L, Orban G (1997) The kinetic occipital region in human visual cortex. Cereb Cortex 7283 292

Dürsteler MR, Wurtz RH (1988) Pursuit and optokinetic deficits following chemical lesions of cortical areas MT and MST. J Neurophysiol 60:940-965

Ernst T, Hennig J (1994) Observation of a fast response in functional MR. Magn Reson Med 32:146-149

Felblinger J, Müri RM, Ozdoba C, Schroth G, Hess CW, Boesch C (1996) Recordings of eye movements for stimulus control dur- 
ing fMRI by means of electro-oculographic methods. Magn Reson Med 36:410-414

Felleman DJ, Van Essen DC (1991) Distributed hierarchical processing in the primate cerebral cortex. Cereb Cortex 1:1-47

Gegenfurtner KR, Kiper DC, Levitt JB (1997) Functional properties of neurons in macaque area V3. J Neurophysiol 77:1906-1923

Gottlieb JP, Bruce CJ, MacAvoy MG (1993) Smooth eye movements elicited by microstimulation in the primate frontal eye field. J Neurophysiol 69:786-799

Greenlee MW, Smith AT (1997) Detection and discrimination of first- and second-order motion in patients with unilateral brain damage. J Neurosci 17:804-818

Greenlee MW, Lang H-J, Mergner T, Seeger W (1995) Visual shortterm memory of stimulus velocity in patients with unilateral posterior brain damage. J Neurosci 15:2287-2300

Kimmich H, Pinow C, Mergner T, Greenlee MW (1995) Smooth pursuit eye movements in patients with impaired visual motion perception. In: Mergner T, Hlavacka F (eds) Multisensory control of posture. Plenum Press, New York, pp 325-329

Komatsu H, Wurtz R H (1988) Relation of cortical areas MT and MST to pursuit eye movements. III. Interaction with full-field visual stimulation J Neurophysiol 60:621-644

Kwong KK, Belliveau JW, Chesler DA, Goldberg IE, Weiskoff RM, Poncelet BP, Kennedy DN, Hoppel BE, et al. (1992) Dynamic magnetic resonance imaging of human brain activity during primary sensory stimulation. Proc Natl Acad Sci USA 89:56755679

Lacina T, Greenlee MW, Mader I, Roser W, Dellas S, Radü EW (1995) fMRI evidence for selective activation of extrastriate cortex by Fourier motion (abstract). Radiology [Suppl] 197:369

Lisberger SG, Morris EJ, Tychsen L (1987) Visual motion processing and sensory-motor integration for smooth pursuit eye movements. Annu Rev Neurosci 10:97-129

Lynch JC (1987) Frontal eye field lesions disrupt visual pursuit. Exp Brain Res 68:437-441

Menon RS, Ogawa S, Hu X, Strupp JP, Anderson P, Ugurbil K (1995) BOLD based functional MRI at $4 \mathrm{~T}$ includes a capillary bed contribution: echo-planar imaging correlates with previous optical imaging using intrinsic signals. Magn Reson Med 33: 453-9

Mikami A, Newsome WT, Wurtz RH (1986) Motion selectivity in macaque visual cortex. I. Mechanisms of direction and speed selectivity in extrastriate area MT. J Neurophysiol 55:1308-1327

Nobre AC, Sebestyen GN, Gitelman DR, Mesulam MM, Frackowiak RSJ, Frith CD (1997) Functional localization of the system for visuospatial attention using positron emsission tomography. Brain 120:515-533

Newsome WT, Mikami A, Wurtz RH (1986) Motion selectivity in macaque visual cortex. III. Psychophysics and physiology of apperent motion. J Neurophysiol 55:1340-1351

O'Craven KM, Rosen BR, Kwong KK, Triesman A, Savoy RL (1997) Voluntary attention modulates fMRI activity in human MT-MST. Neuron 18:591-598

Ogawa S, Lee TM, Nayak AS, Glynn P (1990) Oxygenation-sensitive contrast in magnetic resonance image of rodent brain at high magnetic fields. Magn Reson Med 14:68-78

Ogawa S, Menon R, Tank DW, Kim SG, Merkle H, Ellermann JM, Ugurbil K (1992) Functional brain mapping by blood oxygen- ation dependent contrast magnetic resonance imaging. Biophysics J 64:803-812

Oram MW, Perrett DI (1996) Integration of form and motion in the anterior superior temporal polysensory area (STPa) of the macaque monkey. J Neurophysiol 76:109-129

Petit L, Clark VP, Ingeholm J, Haxby JV (1997) Dissociation of saccade-related and pursuit-related activation in human frontal eye fields as revealed by fMRI. J Neurophysiol 77:3386-3390

Plant GT, Laxer KD, Barbaro NM, Schiffman JS, Nakayama K (1993) Impaired visual motion perception in the contralateral hemifield following unilateral posterior cerebral lesions in humans. Brain 116:1303-1335

Smith AT, Greenlee MW, Singh KD, Kraemer FM, Hennig J (1997) The processing of first- and second-order motion in human visual cortex assessed by functional magnetic resonance imaging (fMRI). (in press)

Talairach J, Tournoux P (1988) Co-planar stereotaxic atlas of the human brain. Thieme, Stuttgart

Tanaka K, Saito HA (1989) Analysis of motion of visual field by direction, expansion/contraction and rotation cells clustered in the dorsal part of MST of the macaque. J Neurophysiol 62:626-641

Tanaka K, Hikosaka K, Saito H, Yukie M, Fukada Y, Iwai E (1986) Analysis of local and wide-field movements in the superior temporal visual areas of the macque monkey. J Neurosci 6:134-144

Tanaka K, Fukada Y, Saito HA (1989) Underlying mechanisms of the response specificity of expansion/contraction and rotation cells in the dorsal part of the medial superior temporal area of the macaque monkey J Neurophysiol 62:642-656

Tootell RBH, Reppas JB, Kwong KK, Malach R, Born RT, Brady TJ, Rosen BR, Belliveau JW (1995) Functional analysis of human MT and related visual cortical areas using magnetic resonance imaging. J Neurosci 15:3215-30

Tootell RBH, Mendola JD, Hadjikhani NK, Ledden PJ, Liu AK, Reppas JB, Sereno MI, Dale AM (1997) Functional analysis of V3A and related areas in human visual cortex. J Neurosci 17:7060-7078

Turner R, Jezzard P, Wen H, Kwong KK, Le Bihan D, Zeffiro T, Balaban RS (1993) Functional mapping of the human visual cortex at 4 and 1.5 tesla using deoxygenation contrast EPI. Magn Reson Med 29:277-9

Van Essen DC, Zeki SM (1978) The topographic organization of rhesus monkey prestriate cortex. J Physiol (Lond) 277:193-226

Van Essen DC, Maunsell JHR, Bixby JL (1981) The middle temporal visual area in the macaque: myeloarchitecture, connections, functional properties and topographic organization. J Comp Neurol 199:293-326

Van Oostende S, Sunaert S, Van Hecke P, Marchal G, Orban GA (1997) The kinetic occipital (KO) region in man: an fMRI study. Cereb Cortex 7:690-701

Watson JD, Myers R, Frackowiak RS, Hajnal JV, Woods RP, Mazziotta JC, Shipp S, Zeki S (1993) Area V5 of the human brain: evidence from a combined study using positron emission tomography and magnetic resonance imaging. Cereb Cortex 3:79-94

Zeki S, Watson JDG, Lueck CJ, Friston KJ, Kennard C, Frackowiak RSJ (1991) A direct demonstration of functional specialization in human visual cortex. J Neurosci 11:641-649 